\title{
Automated slice sensitivity profile measurement of the CT image of the AAPM CT performance phantom: Which stair object should be used?
}

Nani Lasiyah

Diponegoro University: Universitas Diponegoro

Choirul Anam ( $\square$ anam@fisika.fsm.undip.ac.id)

Diponegoro University https://orcid.org/0000-0003-0156-6797

Eko Hidayanto

Diponegoro University: Universitas Diponegoro

Geoff Dougherty

California State University Channel Islands

\section{Research Article}

Keywords: CT scanner, slice thickness, SSP, FWHM, AAPM CT performance phantom

Posted Date: April 15th, 2021

DOI: https://doi.org/10.21203/rs.3.rs-283773/v1

License: (c) (i) This work is licensed under a Creative Commons Attribution 4.0 International License. Read Full License 


\section{Abstract}

Purpose: We used an improved algorithm to automatically measure the slice sensitivity profile (SSP) and its full-width at half maximum (FWHM) from all three stair objects within an image of the AAPM CT performance phantom.

Methods: The phantom was scanned with a Philips Ingenuity 128-slice CT scanner using slice thicknesses of $1 \mathrm{~mm}$ and $5 \mathrm{~mm}$. The three stair objects were named top \#1, middle \#2, and bottom \#3. The software was able to measure the SSP and its FWHM form object \#1,\#2,\#3, and all objects. The SSPs and FWHMs from each stair object were compared with manual measurements.

Results: The FWHM values for a slice thickness of $1 \mathrm{~mm}$ were $1.3 \pm 0.1 \mathrm{~mm}$ for all the stair objects. The FWHM values for a slice thickness of $5 \mathrm{~mm}$ were $5.2 \pm 0.1 \mathrm{~mm}, 5.1 \pm 0.3 \mathrm{~mm}, 5.2 \pm 0.1 \mathrm{~mm}$ for the top, bottom, and middle stair objects, respectively. The results of manual measurements had the same trend as those of the automated measurements.

Conclusion: The improved algorithm for measuring SSP and its FWHM from any stair object within the AAPM performance phantom was successfully developed. The SSPs and their FWHM values measured from every stair object were similar $(p>0.05)$.

\section{Introduction}

The slice sensitivity profile (SSP) of a computed tomography (CT) scanner represents the spatial resolution in the Z-direction [1], and its full width at half maximum (FWHM) corresponds to the effective slice thickness of the image [2-4]. The slice thickness of CT scanners has improved from 5 to $10 \mathrm{~mm}$ [5] down to sub millimeter thicknesses [6-8]. By reducing the slice thickness, a better image resolution can be obtained.

Slice thickness is monitored as part of a regular quality control (QC) program. The purpose of QC is to regularly maintain a consistent image quality over the lifetime of the diagnostic radiology equipment and to ensure safe and accurate operation of the imaging process as a whole [9]. Importantly, it permits the identification of image quality degradation before it affects the interpretation of an image. QC is conducted to locate the source of any possible equipment malfunction and subsequently to conduct immediate maintenance requirements $[9,10]$.

Measurements of the full width of half maximum (FWHM) of the SSP have been conducted using several commercial phantoms, including the Catphan, ASMR, and AAPM CT phantoms [11-14], while several studies developed specific phantoms for their own systems [15-18]. Measurement of the FWHM of SSP using the AAPM CT performance phantom is focused on the stair objects, and a previous study reported that the discrepancy from the nominal slice thickness is about $19 \%$ [19]. 
Determination of the FWHM of the SSP is usually conducted utilizing manual measurement. An automated measurement of SSP on the AAPM CT performance phantom has been developed [20] and provides a more objective and accurate result. However, it only used the middle stair object at a single slice thickness of $5 \mathrm{~mm}$ [20]. The results showed that the automated method could provide accurate measurement results even if the phantom was arbitrary rotated [20]. In fact, there are three stair objects within the AAPM CT performance phantom. Measurement of all of them should give a more accurate and consistent result compared to measuring only the middle object. Hence, in this study, we develop an automated FWHM measurement of SSP of all stair objects (top, middle, and bottom). We compared the results of the measurements for each stair object and used two different slice thicknesses, i.e. 1.0 and 5.0 $\mathrm{mm}$.

\section{Methods}

The CT scanner was a Philips Ingenuity 128-slice CT scanner installed at the radiology installation of Diponegoro National Hospital (RSND), Semarang. The phantom used was a AAPM CT performance phantom (model 610, CIRS, Virginia, US) which comprises three pieces of aluminum, each with a size of $0.635 \times 25.4 \mathrm{~mm}$. Three aluminum objects were positioned at an angle of $45^{0}$ from axis rotation, to produce stair objects within an axial image. The width of the stair objects depends on the nominal slice thickness. The phantom was filled with water. The three angled aluminum plates are as shown in Fig. 1 (a). The phantom was scanned by a CT scanner at two slice thicknesses ( $1 \mathrm{~mm}$ and $5 \mathrm{~mm}$ ) with the acquisition parameters tabulated in Table 1. Figure 1 (b) and Fig. 1 (c) show the resulting images for both slice thickness values.

Table 1

Acquisition parameters used in the scanning process.

\begin{tabular}{|lll|}
\hline Acquisition parameter & Unit & Quantity \\
\hline Tube potential & $\mathrm{kV}$ & 120 \\
\hline Tube current & $\mathrm{mA}$ & 200 \\
\hline Mode & - & Helical \\
\hline Pitch & - & 0.984 \\
\hline Field of view (FOV) & $\mathrm{mm}$ & 260 \\
\hline Rotation time & $\mathrm{S}$ & 1 \\
\hline Reconstruction filter (FBP) & - & Lung \\
\hline Slice thickness & $\mathrm{mm}$ & 1 and 5 \\
\hline
\end{tabular}

All images obtained from the scanning process were saved in DICOM format. Image processing to obtain the FWHM of SSP or slice thickness was carried out using both automated and manual measurements. 
Manual measurement was used to validate the accuracy of the results from automated measurements.

\section{Automated measurement}

The algorithm for automated SSP measurement of the three stair objects was an improvement of a previous algorithm [20] which only used one middle stair object. The algorithm was implemented using the MATLAB R2015b. The three stair objects were named top \#1, middle \#2, and bottom \#3. Figure 2 shows the processes of automated SSP measurement for one specific slice thickness.

There were several steps to determine the SSP and its full-width at half maximum (FWHM). The image was binarized using an appropriate threshold value (Fig. 2b). The middle object was used to determine the angle of the phantom using the Hough Transform in one dimension [21] (Fig. 2c). The angle was determined as the angle for the minimum value of the resulting curve. Based on this angle, every stair object was cropped and rotated. The profiles across the stair objects were obtained and corresponding FWHMs were automatically determined (Fig. 2d). The GUI to determine the SSP and its FWHM is shown in Fig. 3. The user can choose any of the stairs individually, or the average of all three.

\section{Manual measurement}

The manual measurements were performed for comparison with automated measurement, using the IndoseCT software [22]. The manual measurement was done for all three objects at both slice thicknesses. The image was zoomed in, and a line for measuring the width of the stair objects was constructed. The starting and end points of the line were manually and subjectively determined.

The results of manual and automated FWHM measurements from one stair object (top, middle, or bottom) and mean value of all stair objects were compared. Significant difference was tested using the Mann-Whitney $U$ test. A $p$-value less than 0.05 was considered to indicate a statistically significant difference.

\section{Results}

Figure 4. The SSPs and their FWHM values for a slice thickness of $1 \mathrm{~mm}$ of (a) the top stair object \#1; (b) the middle stair object \#2; (c) the bottom stair object \#3, and (d) all the stair objects (mean value). 
Table 2

The automated and manual measurements of FWHM results of the top, middle, bottom stair objects, as well as the mean values of three stair objects. Measurements were carried out for three different slice locations.

\begin{tabular}{|c|c|c|c|c|c|c|c|}
\hline \multirow{2}{*}{$\begin{array}{l}\text { Slice } \\
\text { thickness } \\
(\mathrm{mm})\end{array}$} & \multirow[t]{2}{*}{ Object } & \multicolumn{3}{|c|}{ Automated measurement } & \multicolumn{3}{|c|}{ Manual measurement } \\
\hline & & $\begin{array}{l}\text { FWHM } \\
(\mathrm{mm})\end{array}$ & $\begin{array}{l}\text { Mean } \pm \text { SD of } \\
\text { FWHM }(\mathrm{mm})\end{array}$ & $\begin{array}{l}p- \\
\text { value* }\end{array}$ & $\begin{array}{l}\text { FWHM } \\
(\mathrm{mm})\end{array}$ & $\begin{array}{l}\text { Mean } \pm \text { SD of } \\
\text { FWHM }(\mathrm{mm})\end{array}$ & $\begin{array}{l}p- \\
\text { value* }\end{array}$ \\
\hline \multirow[t]{12}{*}{$1 \mathrm{~mm}$} & \multirow[t]{3}{*}{ top \#1 } & 1.3 & \multirow[t]{3}{*}{$1.3 \pm 0.0$} & \multirow[t]{3}{*}{1.0} & 1.8 & \multirow[t]{3}{*}{$1.9 \pm 0.1$} & \multirow[t]{3}{*}{0.7} \\
\hline & & 1.3 & & & 1.9 & & \\
\hline & & 1.4 & & & 1.9 & & \\
\hline & \multirow{3}{*}{$\begin{array}{l}\text { middle } \\
\# 2\end{array}$} & 1.3 & \multirow[t]{3}{*}{$1.3 \pm 0.1$} & \multirow[t]{3}{*}{1.0} & 1.9 & \multirow[t]{3}{*}{$1.8 \pm 0.1$} & \multirow[t]{3}{*}{1.0} \\
\hline & & 1.3 & & & 1.7 & & \\
\hline & & 1.4 & & & 1.8 & & \\
\hline & \multirow{3}{*}{$\begin{array}{l}\text { bottom } \\
\# 3\end{array}$} & 1.3 & \multirow[t]{3}{*}{$1.3 \pm 0.0$} & \multirow[t]{3}{*}{0.3} & 1.6 & \multirow[t]{3}{*}{$1.6 \pm 0.1$} & \multirow[t]{3}{*}{0.3} \\
\hline & & 1.3 & & & 1.7 & & \\
\hline & & 1.2 & & & 1.5 & & \\
\hline & \multirow{3}{*}{$\begin{array}{l}\text { mean } \\
\text { value }\end{array}$} & 1.4 & \multirow[t]{3}{*}{$1.3 \pm 0.0$} & \multirow[t]{3}{*}{-} & 1.9 & \multirow[t]{3}{*}{$1.8 \pm 0.2$} & \multirow[t]{3}{*}{-} \\
\hline & & 1.4 & & & 1.6 & & \\
\hline & & 1.3 & & & 1.8 & & \\
\hline \multirow[t]{11}{*}{$5 \mathrm{~mm}$} & \multirow[t]{3}{*}{ top \#1 } & 5.1 & \multirow[t]{3}{*}{$5.2 \pm 0.1$} & \multirow[t]{3}{*}{1.0} & 5.1 & \multirow[t]{3}{*}{$5.2 \pm 0.3$} & \multirow[t]{3}{*}{0.6} \\
\hline & & 5.3 & & & 5.6 & & \\
\hline & & 5.2 & & & 5.0 & & \\
\hline & \multirow{3}{*}{$\begin{array}{l}\text { middle } \\
\# 2\end{array}$} & 5.3 & \multirow[t]{3}{*}{$5.2 \pm 0.1$} & 1.0 & 5.1 & $5.2 \pm 0.2$ & 0.4 \\
\hline & & 5.3 & & & 5.0 & & \\
\hline & & 5.1 & & & 5.4 & & \\
\hline & bottom & 5.2 & $5.1 \pm 0.3$ & 1.0 & 5.5 & $5.5 \pm 0.2$ & 0.3 \\
\hline & & 5.4 & & & 5.4 & & \\
\hline & & 4.8 & & & 5.7 & & \\
\hline & mean & 5.3 & $5.2 \pm 0.2$ & - & 5.2 & $5.3 \pm 0.2$ & - \\
\hline & & 5.2 & & & 5.5 & & \\
\hline
\end{tabular}




\section{1}

5.2

*) between one object and mean value of all objects

\section{Discussion}

This study developed an improved automated method for SSP measurement using all stair objects within the image of the AAPM CT performance phantom. Previously, the algorithm used only the middle stair object [20]. Since there are three stair objects within the AAPM CT performance phantom and the image may not homogeneous, investigation of SSPs and their FWHM values for every stair object is important. In addition, measurement of mean of all objects should give a consistent result compared to measuring only one middle object.

As expected, we found that the SSPs and their FWHM values measured from every stair object are similar ( $p$ > 0.05). The FWHMs for all measurements were $1.3 \mathrm{~mm}$ and $5.2 \mathrm{~mm}$ for nominal slice thicknesses 1.0 $\mathrm{mm}$ and $5.0 \mathrm{~mm}$, respectively. The finding of the automated results was confirmed by the manual method (Table 2).

Although, the measurements were only carried out on two different slice thickness, the results may be applicable for any nominal slice thickness. Our software is specifically for images of the AAPM CT performance phantom and is not applicable to other phantoms.

According to the International Society of Radiographers \& Radiological Technologists (ISRRT), the criteria for acceptance is that the measured slice thickness should not exceed $0.5 \mathrm{~mm}$ for nominal slice thicknesses $<5 \mathrm{~mm}$, and should not exceed $1 \mathrm{~mm}$ for nominal slice thicknesses above $5 \mathrm{~mm}$ [10]. In this particular the discrepancies were below $0.5 \mathrm{~mm}$.

It was found that reducing the slice thickness reduced the accuracy of SSP. Compared to the manual method, the automated measurement provided more accurate and consistent measurement results for all the stair objects.

\section{Conclusions}

The improved algorithm for measuring SSP and its FWHM from any stair object within the AAPM performance phantom was successfully developed. We found that the SSPs and their FWHM values measured from every stair object were similar $(p>0.05)$. The FWHMs for all measurement were $1.3 \mathrm{~mm}$ and $5.2 \mathrm{~mm}$ for nominal slice thicknesses $1.0 \mathrm{~mm}$ and $5.0 \mathrm{~mm}$, respectively. The automated measurement method provided more accurate results compared to the manual measurement.

\section{Declarations}




\section{Compliance with Ethical Standards:}

The authors declare that this manuscript has not been published previously nor concurrently submitted for publication elsewhere.

Funding: This study was funded by the World Class Research University, Diponegoro University, 2021.

Conflict of Interest: All authors declare that they have no conflict of interest.

Ethical approval: This article does not contain any studies with human participants or animals performed by any of the authors.

\section{References}

1. Romans LE (2011) Computer tomography for technologiests: A comprehensive text. Wolter Health Lippincott Williams \& Wilkins

2. Van der Molen AJ, Joemai RM, Geleijns J (2012) Performance of longitudinal and volumetric tube current modulation in a 64-slice CT with different choices of acquisition and reconstruction acquisition and reconstruction. Phys Med 28:319-326

3. Raman SP, Mahesh M, Blasko RV, Fishman EK (2013) CT scan parameters and radiation dose: Practical advice for radiologists. J Am Coll Radiol 10:840-846

4. Nugroho RA, Ardiyanto J, Wijokongko S (2020) Analisis variasi slice thickness terhadap informasi anatomi potongan axial pada pemeriksaan MSCT cervical pada kasus trauma. Jurnal Imejing Diagnostik 6:91-95

5. Hsieh J (2009) Computed tomography: Principle, design, artifacts, and recent advances, Second Edition, SPIE and John Wiley \& Sons, Inc

6. Hostetler ZS, Stitzel JD, Weaver AA (2019) Comparing rib cortical thickness measurements from computed tomography (CT) and Micro-CT. Comput Biol Med 111:103330

7. Moshfeghi M, Amintavakoli M, Ghaznavi D, Ghaznavi A (2016) Effect of slice thickness on the accuracy of linear measurements made on cone beam computed tomography images (InVitro). Journal of Dental School Shahid Beheshti University of Medical Sciences 34:100-108

8. Grieser C, Steffen IG, Gartenschläger S, Stiepani H, Fernandez CMP, Hamm B, Denecke T (2011) Assessment of the cerebellar arteries with multidetector computed tomography angiography benefits from submillimeter slice thickness. Clin Imaging 35:247-252

9. Vermiglio G, Acri G, Testagrossa B, Causa F, Tripepi MG (2011) Procedures for evaluation of slice thickness in medical imaging systems. In: Eldin AB (ed) Modern approaches to quality control. InTech

10. Das IJ, Cao M, Cheng C, Misic V, Scheuring K, Schüle E, Johnstone PAS (2011) A quality assurance phantom for electronic portal imaging devices. J Appl Clin Med Phys 12:391-403 
11. Roa AMA, Andersen HK, Martinsen ACT (2015) CT image quality over time: comparison of image quality for six different CT scanners over a six-year period. J Appl Clin Med Phys 16:350-365

12. Mansour Z, Mokhtar A, Sarhan A, Ahmed M, El-Diasty T (2016) Quality control of CT image using American College of Radiology (ACR) phantom. The Egyptian Journal of Radiology Nuclear Medicine 47:1665-1671

13. Mulyadin DS, Abdullah B, Tahir D (2018) Study of image quality from CT scanner multi-detector byusing Americans College of Radiology (ACR) phantom. Journal of Physics: Conf Series 979:012080

14. Noh SS, Um HS, Kim HC (2014) Development of automatized quantitative analysis method in CT images evaluation using AAPM phantom. Journal of the Institute of Electronics Information Engineers 51:163-173

15. Allert KD, Vangala S, DiBianca FA (2007) Novel materials for low-contrast phantoms for computed tomography. J Xray Sci Technol 15:9-18

16. Goldoost B, Ebrahimpoor M, Behrouzkia Z, Aghdam RZ, Refahi S (2018) Assessment of water CT number, field uniformity and noise in diagnostics computed tomography scanners in Urmia metropolis, Iran. International Journal of Advanced Biotechnology Research 9:165-170

17. Coolens C, Mohseni H, Dhodi S, Keller H, Ma S, Jaffray DA (2018) Quantification accuracy for dynamic contrast enhanced (DCE) CT imaging: phantom and quality assurance framework. Eur J Radiol 106:192-198

18. Sharma DS, Sharma SD, Sanu KK, Saju S, Deshhpande DD, Kannan S (2006) Performance evaluation of a dedicated computed tomography scanner used for virtual simulation using in-house fabricated CT phantoms. J Med Phys 31:28-35

19. Makmur IWA, Setiabudi W, Anam C (2015) Evaluasi ketebalan irisan (slice thickness) pada pesawat CT-scan single slice. Jurnal Sains dan Matematika 21:42-47

20. Sofiyatun S, Anam C, Zahro U, Rukmana D, Dougherty G (2020) An automated measurement of image slice thickness of computed tomography. in: International Conference and School on Physics in Medicine and Biosystems, pp. 12-13

21. Anam C, Arif I, Haryanto F, Widita R, Lestari FP, Adi K, DoughertyG (2019) A simplified method for the water-equivalent diameter calculation to estimate patient dose in CT examinations. Radiat Prot Dosimetry 185:42-49

22. Anam C, Haryanto F, Widita R, Arif I, Dougherty G, McLean D (2018) Volume computed tomography dose index $\left(\mathrm{CTDI}_{\mathrm{vol}}\right)$ and size-specific dose estimate (SSDE) for tube current modulation (TCM) in CT scanning. Int J Radiat Res 16:289-297

\section{Figures}




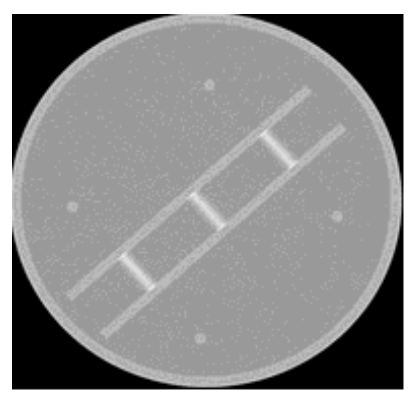

(a)

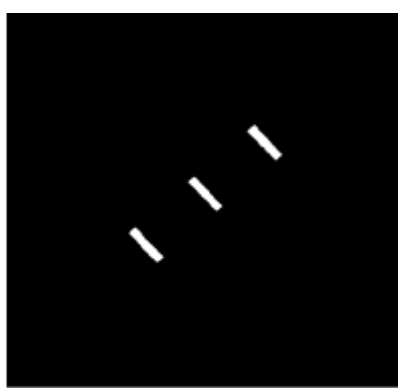

(b)

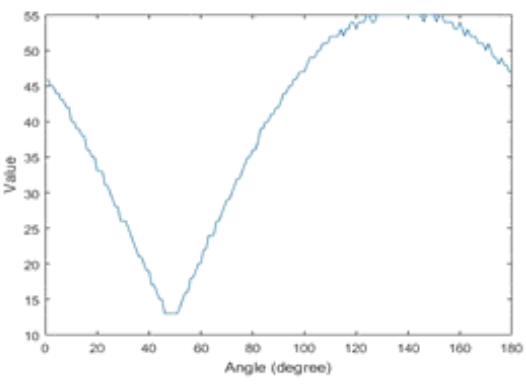

(c)

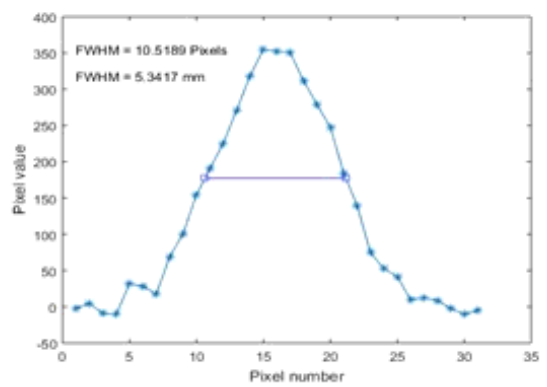

(d)

\section{Figure 2}

Automated measurement process (a) the original image of the object; (b) after image segmentation (c) the resulting graph after Hough transformation to determine the angle of the phantom; (d) average SSP of FWHM in units of pixel and $\mathrm{mm}$. 